\title{
Discussion on the Basic Idea of Informatization Construction on Equipment Support in PAP
}

\author{
Zhe Xin $\operatorname{Han}^{1, a}$, Chao Zu Ma ${ }^{2, b}$ \\ ${ }^{1}$ Department of Information Engineering, Officers College of PAP, Chengdu 610213, China; \\ ${ }^{2}$ Department of Management Science and Project, Officers College of PAP, Chengdu 610213, \\ China \\ a328693098@qq.com, ${ }^{\text {b} 1013328070 @ q q . c o m ~}$
}

Keywords: informationization, equipment support, countermeasure, PAP.

\begin{abstract}
In order to realize the synchronization of informatization construction on equipment support in PAP, it's necessary to achieve the goal of "Quick Response". This paper analyzes the possibility, reality and necessity of the application on information technology in the equipment support in PAP based on deep analysis of the scientific connotation on equipment safeguard informatization. According to some existing problems in the equipment support informatization, the corresponding improvement measures and countermeasures are put forward.
\end{abstract}

\section{Preface}

Informatization is one of the three key points in the modernization in PAP, and the equipment support system based on information technology is an important symbol of the modernization [1]. Equipment safeguard informatization is the inevitable requirement of the construction on equipment support, and the rapid development of information technology for equipment safeguard informatization provides strong technical supports and a vital opportunity to realize equipment safeguard informatization in PAP. We must seize the opportunity, face the challenge, carry out the feasible development strategy, and accelerate the implementation process of equipment informatization.

\section{The connotation of construction on the informatization for equipment support}

Equipment safeguard informatization is the use of advanced information technology and information equipment to establish the information infrastructure equipment which is necessary in the area of materiel support in PAP. It also requires to vigorously collect information of weapons and equipment procurement, storage, supplement, management, training and retirement [2]. Implementation of equipment safeguard informatization requires information as the important resources of war and guaranteed resources, and assume weaponry as an information platform to achieve the high degree of integration of information technology and equipment security.

For the concept of equipment support information, we can make further understanding from the following aspects:

(1) Equipment safeguard informatization is the product of information technology in the field of equipment support. It is the fundamental driving force for the realization of the modernization for equipment support.

(2) The scope of equipment safeguard informatization relates to all aspects of equipment support system in each link and all kinds of security activities, including equipment support information management, equipment technical support informatization, equipment support command informatization, equipment safeguard informatization and so on. 


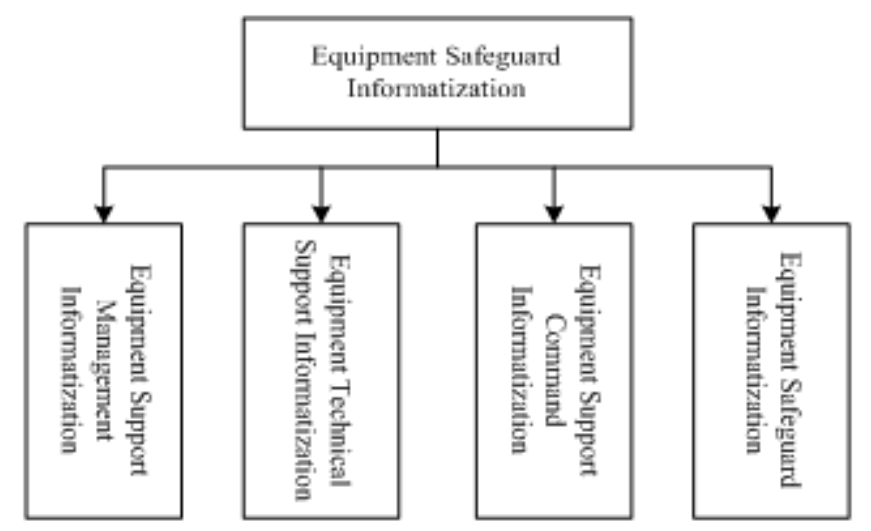

Fig. 1 The scope of equipment safeguard informatization

(3) Equipment safeguard informatization must have the corresponding organizational guarantees, so that the whole system can work smoothly, which provides a platform to display its own information superiority.

3. The possibility, reality and necessity of the application for equipment support informatization in PAP

Equipment construction should focus on the specific requirements, pointing out the problems of the deficiency upon independent R\&D ability, poor integration and lack of special equipment. Informatization construction should pay much attention on the goal of "One strengthening and Four modernizations", focused on solving difficulties in the imperfect network infrastructure, un-matching information system and the relative lagging soft-wars [3,4]. Due to our national conditions, the level of science and technology are distinct from the western developed countries, it cannot completely copy the mode. However, we can learn, emulate some part of the Liberation Army and the western developed countries in its construction of equipment safeguard informatization which should be a basic idea of the construction on equipment support in PAP.

\section{Countermeasures and suggestions on the informatization construction for the equipment support in PAP}

\subsection{To strengthen the construction of equipment structure}

In terms of forces, the General Equipment Department is the leading organs of military equipment in charge of equipment works. As far as the armed police force is concerned, the equipment leading group is the leading organization of equipment works and its office is located in the headquarters of the Department of equipment. The Ministry of command on equipment is the vanguard sector of the whole team equipment which responsible for the organization of weaponry research, procurement, distribution and macro management [5].

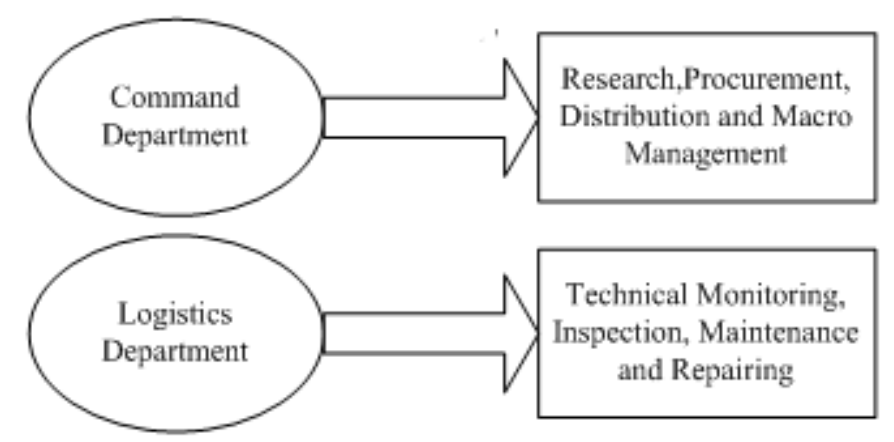

Fig.2 Forms of equipment management in PAP

The existing structural system has brought great difficulty to the equipment support informatization work. Therefore, we must speed up the transformation of the logistics equipment 
system in PAP, accelerating on optimization adjustment and reconstruction of existing equipment sectors [6], coupling as one comprehensive security system in all agencies and levels which play a greater logistical support force.

\subsection{To strengthen equipment constructions of integrated commanding}

Through all levels of the equipment auto-command system and the utilization of Internet, security unit and resources to a complementary unity could carry out unified planning, management and command, improved the timeliness and accuracy of equipment support.

To improve the "Three networks and One system" as the subject of the information infrastructure, optimizing confidential information security system and fully distributing commanding vehicle [7]. It will be built into a multi-efficient integrated commanding system including commanding center as a fixed commanding platform, integrated commanding vehicle for mobile commanding platform, field commanding truck as a field commanding platform,. It basically realizes the purpose of full-process controlling, real-time commanding and situational awareness.

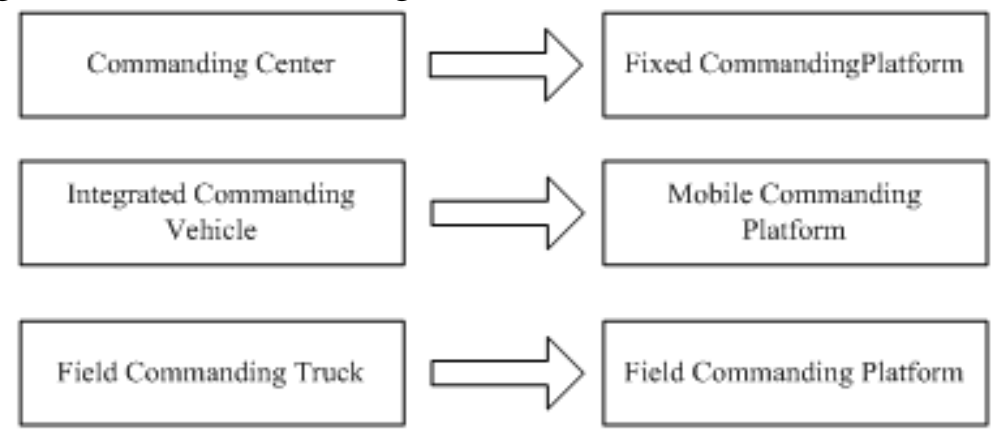

Fig. 3 Integrated commanding system

\subsection{To strengthen basic information network construction of equipment support}

Information network is the highway to ensure fast interactive operation.

According to the principle of " Vertically through all levels, horizontally coverage all elements, external effective access, internal integration", it need to build a information security network which throughout the headquarters, corps (motorized division, headquarters, institutions), detachment (Regiment) level command post, integrated operations, intelligence, communications, equipment, political divisions, logistical and other commanding elements and realize goals of sharing resources by State and Military Emergency Management Department. At the same time, the equipment departments at all levels should do a good job in the information network connection with local equipment, scientific research, production, maintenance and other related units, ensuring the integration of equipment support at multi-level, multi-field and multi-aspects.

\section{Concluding remarks}

Construction of Equipment support informatization is accompanied by global informatization to promote China's information and strategy implementation. Only on the weaponry informatization construction of full analysis can we truly achieve sound and fast development in PAP.

\section{References}

[1] Zhang Renjun. Equipment science in PAP[M]. Shaanxi: Engineering University of PAP, 2012.3-23.

[2] Zhou Likun. Equipment support information[M]. Beijing:The People Armed Police Press, 2011.10-17.

[3] Xu Zhijun. Research on accelerating the construction of informatization in Armed Police[J]. Journal of PLA University of Science and Technology(Natural Science Edition), 2002(4):23- 26. 
[4] Zhang Zhenzhong. Research on information technology of equipment support[J]. Journal of Academy of Armored Force Engineering, 2004(3):13- 17.

[5] An Linlei, Bai Yanqi, Wang Sugang. Research on the issue for the countermeasures of construction on equipment supporting information [J]. Logistics technology, 2007(1).

[6] Wei Yufu, Yang Jinping, Lu Shouxiong, Ye Xiangbing. The influence of information construction on equipment support and its Countermeasures[J]. Xiang Chao (second half), 2009(3).

[7] Huang Baoguo, Li Qing. Research on informatization of equipment support[C]. Beijing: The people's Liberation Army press. 2003.421-442. 